\title{
Electronic brachytherapy management of atypical fibroxanthoma: report of 8 lesions
}

\author{
Stephen Doggett, MD', James Brazil, MD², Marketa Limova, MD³, Leah Press, MD³, Sidney Smith, MD4, Jeremy Peck, MD, PhD4 \\ 'Aegis Oncology, Tustin, CA, ${ }^{2}$ Olympic Dermatology, Olympia, WA, ${ }^{3}$ Minarets Medical Group, Fresno, CA, ${ }^{4}$ DermaHealth Dermatology \\ \& Dermasurgery, Richland, WA, USA
}

\begin{abstract}
Purpose: To evaluate the suitability of treating atypical fibroxanthoma (AFX), an uncommon skin malignancy, with electronic brachytherapy.

Material and methods: From Feb 2013 to Sep 2014, we were referred a total of 8 cases of AFX in 7 patients, all involving the scalp. All of them were treated with electronic brachytherapy $50 \mathrm{Kev}$ radiations (Xoft Axxent ${ }^{\circledR}$, Fremont, California). All lesions received $40 \mathrm{~Gy}$ in two fractions per week with $5 \mathrm{~mm}$ margins.

Results: At a median follow-up of 23.7 months, the local recurrence rate is $12.5 \%$. The single lesion that failed was not debulked surgically prior to electronic brachytherapy.

Conclusions: To our knowledge, this is the first report in the literature on the use of radiation therapy as curative primary treatment for AFX. No contraindication to the use of radiations is found in the literature, with surgery being the sole treatment for AFX noted. Our recurrence rate is $0 \%$ for debulked lesions. Risk of recurrence is mitigated with surgical debulking prior to brachytherapy. Electronic brachytherapy appears to be a safe and effective treatment for debulked AFX. Multiple excisions, skin grafting, and wound care can be avoided in elderly patients by the use of electronic brachytherapy.

Key words: atypical fibroxanthoma, electronic brachytherapy, radiation therapy, skin.

\section{Purpose}

Atypical fibroxanthoma (AFX) is an uncommon skin tumor of variable but usually moderate grade malignancy, presenting typically on the scalp of chronically sun exposed skin in elderly white males and skin previously treated with radiotherapy. It is now commonly grouped with malignant fibrous histiocytoma (MFH), with which it shares similar immunohistochemical, histological, and clinical presentation characteristics. Atypical fibroxanthoma and MFH are considered by some authors to represent a type of undifferentiated pleomorphic sarcoma, lacking its more aggressive behavior [1]. The common detection of UV-induced p53 genetic mutations suggest sun exposure as a likely etiology of AFX [2].

Typical presentation is a rapidly growing fungating lesion clinically similar to that seen with poorly differentiated squamous cell carcinoma, keratoacanthoma, or MFH. Dermatologic surgery has traditionally been the first line of therapy for AFX, with a local post-operative recurrence rate of 5-25\% [1,2,3,4,5,6,7]. Recurrences present rapidly, 7.3 to 24 months post-operatively $[2,8,9]$. The literature cites an improvement in local control as well as no improvement in local control with Mohs micrographic surgery, when compared to standard excisional surgery $[3,5]$. The high local recurrence rate may be due to inadequate margins as micrographic surgery in one series has been shown to have a better local control rate, compared to standard excisional surgery, although patient numbers were small and survival was not improved [3]. Another larger series with review of the literature showed no improvement in either local control or survival with micrographic surgery (Mohs microsurgery) compared to wide local excision [5].

The AFX metastasis rate after surgery is around $1-4 \%$ and is associated with large tumors, tumor necrosis, vascular, and deep invasion $[3,4,5,8]$. These metastatic tumors histologically resemble AFX, but may represent misdiagnosis and may conceal a more aggressive neoplasm, such as squamous cell carcinoma, malignant melanoma, or MFH [3]. A PubMed search to 1970 disclosed no literature on the use of radiation therapy as primary treatment for $\mathrm{AFX}$, and no contraindication to the use of radiations for AFX $[2,6,10,11]$. Because of the lack of contraindication to the use of radiations in the literature, we elected to treat AFX with electronic brachytherapy. Patients were treated with a similar dose fractionation schedule used for nonmelanomatous skin cancer (NMSC); 5 Gy twice a week for four weeks treating to the skin surface with $50 \mathrm{kv}$ radiations $[12,13,14,15]$. 
Table 1. Patient characteristics

\begin{tabular}{|c|c|c|c|c|c|c|c|c|}
\hline Pt \# & Age & Site & $\begin{array}{l}\text { Lesion maximum; } \\
\mathrm{X}, \mathrm{Y} \text { dimension }\end{array}$ & $\begin{array}{l}\text { Months follow-up } \\
\text { post treatment }\end{array}$ & $\begin{array}{l}\text { Debulked prior } \\
\text { to radiations }\end{array}$ & Status & $\begin{array}{l}\text { Cone size } \\
\text { [mm] }\end{array}$ & $\begin{array}{l}\text { Time between debulk- } \\
\text { ing and radiations }\end{array}$ \\
\hline 1 & 89 & Scalp & $12 \mathrm{~mm}$ & 27 & yes & NED & 20 & 6 weeks \\
\hline 2 & 75 & Scalp & $20 \mathrm{~mm}$ & 18 & yes & NED & 35 & 4 weeks \\
\hline 3 & 86 & Scalp & $12 \mathrm{~mm}$ & 21 & yes & NED & 35 & 1 week \\
\hline 4 & 86 & Scalp & $22 \mathrm{~mm}$ & 33 & yes & NED & 35 & 8 weeks \\
\hline 5 & 86 & Scalp & $12 \mathrm{~mm}$ & 21 & yes & NED & 35 & 1 week \\
\hline 6 & 95 & Scalp & $13 \mathrm{~mm}$ & 4 & no & RECUR & 35 & 4 weeks \\
\hline 7 & 85 & Scalp & $15 \mathrm{~mm}$ & 22 & yes & NED & 35 & 2 weeks \\
\hline 8 & 66 & Scalp & $8 \mathrm{~mm}$ & 24 & yes & NED & 50 & 12 weeks \\
\hline
\end{tabular}

NED - adjuvant brachytherapy; RECUR - recurrence

To our knowledge, this is the first report in the literature on the use of radiation therapy as curative primary treatment for AFX

\section{Material and methods}

From February 2013 to September 2014, we were referred a total of 8 cases of biopsied AFX in 7 elderly white males and all involving sun exposed scalp. Atypical fibroxanthoma pathology was confirmed by university dermatopathologists in 4 cases, a national dermatopathology laboratory in one, and by the referring dermatopathologist in two.

Lesions were biopsied by shave technique. Punch biopsy was not used, and therefore measurement of depth of lesion was not possible. Consultation with each co-author confirmed that the lesions each presented as a fleshy protuberance, and were shaved via hand held flexible blade flush to the skin surface, leaving bulk disease beneath the level of the epidermis.

All lesions had therefore been surgically rendered flat with bulk disease present below the skin surface at the commencement of radiation therapy, with one exception. This one exception, which was irradiated with visible and palpable tumor above the level of the epidermis, was the sole lesion that recurred. All of them were treated with electronic brachytherapy $50 \mathrm{kV}$ radiations (Xoft Axxent ${ }^{\circledR}$, Fremont,

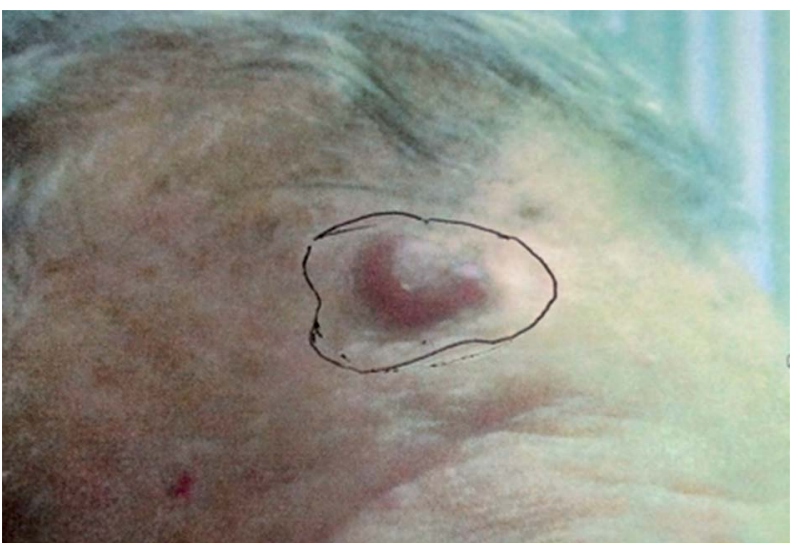

Fig. 1. Scalp atypical fibroxanthoma in an 86-year-old white male prior to shave biopsy
California, USA). All lesions received $40 \mathrm{~Gy}$ in two fractions per week treated to $D_{\max }$. Margins ranged from $4 \mathrm{~mm}$ to 11 $\mathrm{mm}$. Cone size varied from $20 \mathrm{~mm}, 35 \mathrm{~mm}$, and $50 \mathrm{~mm}$ with most lesions treated with the $35-\mathrm{mm}$ cone (Table 1). All patients were treated at the referring dermatologists' office, which permitted close collaboration between the radiation oncologist and the dermatologist in delineating field margins and evaluating amount of residual tumor post biopsy.

Recent technological advances have resulted in the miniaturization of a $50 \mathrm{Kev}$ X-ray source tube (Xoft Axxent ${ }^{\circledR}$ San Jose, California, USA). The source catheter fits into the stainless-steel cone applicator, which is available in several different sizes, allowing treatment of lesions up to $4.5 \mathrm{~cm}$ in diameter. The applicator contains a flattening filter at the apex of the cone, which ensures even dose distribution across the lesion surface. The applicator has a plastic end cap contacting the skin to ensure a flat skin surface for dose homogeneity. The low source energy of $50 \mathrm{Kev}$ in conjunction with the steel shaft eliminates heavy shielding requirements, allowing treatments to be given in any unshielded room. Dosimetry studies have documented the homogenous nature of the X-ray photons generated by the device and the substantially lower doses delivered to surrounding tissues as compared to the doses reached by ${ }^{192} \operatorname{Ir}(350 \mathrm{KeV})$ brachytherapy $[16,17,18,19]$.

The stainless-steel applicators are applied over the skin after selecting the appropriate size applicator based on the

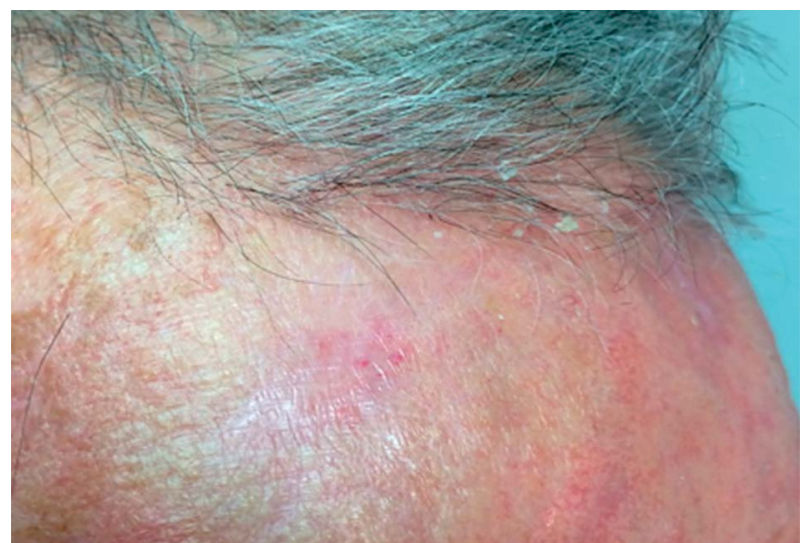

Fig. 2. Scalp four months following shave biopsy and electronic brachytherapy 
size of the lesion. The applicator is held in place with the multi-jointed arm assembly with the end cap contacting and flattening the skin surface, with the patient in a comfortable position. Following quality assurance checks, the $\mathrm{X}$-ray source is activated and radiation treatments are delivered and monitored by the computerized controller. The average treatment time is 2-3 minutes. Most skin sites can be treated with the patient seated comfortably upright.

Because the source is encased by the stainless-steel applicator during the treatment, the only exit for the X-rays is directly onto the skin. $50 \mathrm{Kev} \mathrm{X}$-rays are low energy and have a half value layer of 5-6 mm of water. At 5-6 millimeters of tissue depth, the radiation dose has fallen by half, so tissues underlying the skin receive minimal radiations. Scattered radiations are absorbed by the stainless-steel applicator, so the radiation therapist can remain in the room with the patient during the entire treatment to ensure that there is no shift of the applicator. Close real time supervision of treatment permits applicator selection to more tightly match lesion contours and therefore decrease the amount of normal tissue irradiated.

\section{Results}

As of August 2016, there has been one local recurrence. This was the only lesion that was not debulked surgically prior to electronic brachytherapy. Recurrence rate is $12.5 \%$ at 23.7 month's average follow-up. Recurrence rate is $0 \%$ for debulked lesions. Risk of recurrence is mitigated with surgical debulking prior to brachytherapy. All patients displayed RTOG grade 1-2 acute toxicities (erythema and patchy moist desquamation), which resolved completely with petrolatum based topicals. Chronic RTOG skin toxicities were limited to $0-1$ (mild hair loss, mild pigmentation change, no telangiectasia) in all cases (Figures 1 and 2).

\section{Discussion}

Electronic brachytherapy appears to be a safe and effective treatment for AFX after debulking surgery, even where gross tumor remains. The results of this report of electronic brachytherapy appears comparable to those reported for surgical excision. Multiple excisions, skin grafting, and extensive wound care are avoided in elderly patients with AFX by the use of electronic brachytherapy. Risk of recurrence appears markedly decreased with surgical debulking prior to brachytherapy. Optimal dose fractionation schedules for skin malignancies treated with electronic brachytherapy continue to be investigated $[3,20,21]$. Electronic brachytherapy appears to be an acceptable alternative to surgery for gross AFX, although longer follow-up is needed to confirm equivalence to reported surgical results.

\section{Disclosure}

Authors report no conflict of interest.

\section{References}

1. Withers AH, Brougham ND, Barber RM et al. Atypical fibroxanthoma and malignant fibrous histiocytoma. J Plast Reconstr Aesthet Surg 2011; 64: e273-278.
2. Ziemer M. Atypical fibroxanthoma. J Dtsch Dermatol Ges 2012; 10: 537-550 [Article in English, German].

3. Ang GC, Roenigk RK, Otley CC et al. More than 2 decades of treating atypical fibroxanthoma at mayo clinic: what have we learned from 91 patients? Dermatol Surg 2009; 35: 765-772.

4. Sakamoto A. Atypical fibroxanthoma. Clin Med Oncol 2008; 2: 117-127.

5. Koch M, Freundl AJ, Agaimy A et al. Atypical Fibroxanthoma - Histological Diagnosis, Immunohistochemical Markers and Concepts of Therapy. Anticancer Res 2015; 35: 5717-5735.

6. Hollmig ST, Sachdev R, Cockerell CJ et al. Spindle cell neoplasms encountered in dermatologic surgery: a review. Dermatol Surg 2012; 38: 825-850.

7. Withers AH, Brougham ND, Barber RM et al. Atypical fibroxanthoma and malignant fibrous histiocytoma. J Plast Reconstr Aesthet Surg 2011; 64: e273-278.

8. Davidson JS, Demsey D. Atypical fibroxanthoma: clinicopathologic determinants for recurrence and implications for surgical management. J Surg Oncol 2012; 105: 559-562.

9. Wollina U, Schönlebe J, Koch A et al. Atypical fibroxanthoma: a series of 25 cases. J Eur Acad Dermatol Venereol 2010; 24: 943-946.

10. Mahalingam S, Shah A, Stewart A. Atypical fibroxanthoma: a case series and review of literature. Auris Nasus Larynx 2015; 42: 469-471.

11. Hilgers M, Wahl RU, Megahed M. Atypical fibroxanthoma of the scalp: overview and recent developments. Hautarzt 2014; 65: 1008-1010 [Article in German].

12. Doggett $S$, Willoughby $M$, Willoughby $C$ et al. Incorporation of Electronic Brachytherapy for Skin Cancer into a Community Dermatology Practice. J Clin Aesthet Dermatol 2015; 8: 28-32.

13. Ballester-Sánchez R, Pons-Llanas O, Candela-Juan C et al. Electronic brachytherapy for superficial and nodular basal cell carcinoma: a report of two prospective pilot trials using different doses. J Contemp Brachytherapy 2016; 8: 48-55.

14. Ballester-Sánchez R, Pons-Llanas O, Candela-Juan C et al. Efficacy and safety of electronic brachytherapy for superficial and nodular basal cell carcinoma. J Contemp Brachytherapy 2015; 7: 231-238.

15. Pons-Llanas O, Ballester-Sánchez R, Celada-Álvarez FJ et al. Clinical implementation of a new electronic brachytherapy system for skin brachytherapy. J Contemp Brachytherapy 2015; 6: 417-423.

16. Ahmad S, Johnson D, Hiatt JR et al. Comparison of tumor and normal tissue dose for accelerated partial breast irradiation using an electronic brachytherapy eBx source and an Iridium-192 source. J Appl Clin Med Phys 2010; 11: 3301.

17. Johnson M, Ahmad S, Johnson D. SU-E-T-388: Evaluation of electronic brachytherapy dose distributions in tissue equivalent materials. Med Phys 2015; 42: 3423.

18. Rong Y, Welsh JS. Surface applicator calibration and commissioning of an electronic brachytherapy system for nonmelanoma skin cancer treatment. Med Phys 2010; 37: 5509-5517.

19. Holt RW, Thomadsen BR, Orton CG. Point/counterpoint. Miniature x-ray tubes will ultimately displace Ir-192 as the radiation sources of choice for high dose rate brachytherapy. Med Phys 2008; 35: 815-817.

20. Bhatnagar A, Loper A. The initial experience of electronic brachytherapy for the treatment of non-melanoma skin cancer. Radiat Oncol 2010; 5: 87.

21. Strimling R, et al. Initial experience of Electronic Brachytherapy for the treatment of 508 non-melanoma skin cancers in 308 patients. Presented at the American Academy of Dermatology Annual Meeting [poster presentation 2013]. March 2023, 2015, San Francisco, California. 